\title{
Effect of Different Seed Solutions on the Morphology and Electrooptical Properties of ZnO Nanorods
}

\author{
M. Kashif, ${ }^{1}$ U. Hashim, ${ }^{1}$ M. E. Ali, ${ }^{2}$ Syed M. Usman Ali, ${ }^{3}$ \\ M. Rusop, ${ }^{4}$ Z. H. Ibupoto, ${ }^{5}$ and Magnus Willander ${ }^{5}$ \\ ${ }^{1}$ Institute of Nano Electronic Engineering, Universiti Malaysia Perlis, Seriab, Kangar, 01000 Perlis, Malaysia \\ ${ }^{2}$ Nanotechnology and Catalysis Research Centre, University of Malaya, 50603 Kuala Lumpur, Malaysia \\ ${ }^{3}$ Department of Electronic Engineering, NED University of Engineering and Technology, Karachi 75270, Pakistan \\ ${ }^{4}$ NANO-ElecTronic Centre (NET), Faculty of Electrical Engineering, Universiti Teknologi MARA (UiTM), Selangor, \\ 40450 Shah Alam, Malaysia \\ ${ }^{5}$ Department of Science and Technology, Campus Norrköping, Linköping University, 60174 Norrköping, Sweden
}

Correspondence should be addressed to M. Kashif, kashif_bme@yahoo.com

Received 18 May 2012; Revised 27 August 2012; Accepted 27 August 2012

Academic Editor: Gong Ru Lin

Copyright ( $) 2012$ M. Kashif et al. This is an open access article distributed under the Creative Commons Attribution License, which permits unrestricted use, distribution, and reproduction in any medium, provided the original work is properly cited.

\begin{abstract}
The morphology and electrooptical properties of $\mathrm{ZnO}$ nanorods synthesized on monoethanolamine-based seed layer and $\mathrm{KOH}$ based seed layer were compared. The seed solutions were prepared in monoethanolamine in 2-methoxyethanol and potassium hydroxide in methanol, respectively. Zinc acetate dihydrate was as a common precursor in both solutions. The nanorod-ZnOs were synthesized via the spin coating of two different seed solutions on silicon substrates followed by their hydrothermal growth. The scanning electron microscopy (SEM), X-ray diffraction (XRD), photoluminescence (PL), and Raman studies revealed that the $\mathrm{ZnO}$ nanorods obtained from monoethanolamine-based seed layer had fewer defects, better crystals, and better alignment than those realized via $\mathrm{KOH}$-based seed layer. However, the current-voltage (I-V) characteristics demonstrated better conductivity of the $\mathrm{ZnO}$ nanorods obtained via $\mathrm{KOH}$-based seed layer. The current measured in forward bias was $4 \mathrm{~mA}$ and $40 \mu \mathrm{A}$ for $\mathrm{ZnO}$ nanorods grown on $\mathrm{KOH}$-based seed layer and monoethanolamine-based with the turn on voltage of approximately $1.5 \mathrm{~V}$ and $2.5 \mathrm{~V}$, respectively, showing the feasibility of using both structures in optoelectric devices.
\end{abstract}

\section{Introduction}

Zinc oxide $(\mathrm{ZnO})$ which belongs to II-IV group of semiconducting materials is increasingly getting more and more research interests because of its attractive and fascinating properties such as approximately $3.37 \mathrm{eV}$ of direct wide bandgap and about $60 \mathrm{meV}$ of exciton binding energy. In fact, these properties are suitable for numerous applications in optoelectronic and biomedical devices. For examples micro- and nanostructures $\mathrm{ZnO}$ were successfully used in various sensing appliances such as UV sensors, biosensors (protein, DNA, and cancer cell detection) as well as gas sensors [1-5]. In the last few decades, $\mathrm{ZnO}$-nanostructures with many fascinating forms such as nanorods, nano-flakes, nanorings, and nanoribbons, were synthesized [6-9]. To obtain these structures, various methods such as MOCVD, sol-gel, molecular beam epitaxy, thermal evaporation, and site-selective deposition techniques were documented [1016]. Among these techniques, sol-gel methods have got huge interests because of their reduced growth temperature, reduced cost, and superior simplicity. However, a comparative study of $\mathrm{ZnO}$ nanorods synthesized on monoethanolamine-based seed layer and $\mathrm{KOH}-$ based seed layer using sol-gel method to realize nanorod-ZnOs has yet to be systematically reported.

In this study, nanorod-ZnOs were synthesized on two different seeded substrates and their morphological, crystalline, and optoelectrical properties were systematically studied using SEM, XRD, Raman, and photoluminescence spectroscopies as well as current-voltage profiler. The study reflected that the seed solution prepared through 2-methoxyethanol route is superior to $\mathrm{KOH}$ one to synthesize nanorod- $\mathrm{ZnO}$ 
with less defects, better crystal, and better alignment. On the other hand, the applicability of $\mathrm{KOH}$ route was realized to obtain nanostructured $\mathrm{ZnO}$ with superior conductivity.

\section{Experimental}

2.1. Preparation of Seed Solutions. All chemicals used in this experiment were of the highest available purity and were purchased from Sigma-Aldrich, USA. ZnO seed solutions were prepared in two different solvents, namely, methanol and 2-methoxyethanol. The first solution $(0.01 \mathrm{M})$ was prepared by dissolving $274 \mathrm{mg}$ of zinc acetate dihydrate in $125 \mathrm{~mL}$ of methanol at $60^{\circ} \mathrm{C}$. A potassium hydroxide solution of $0.03 \mathrm{M}$ was prepared by dissolving $109 \mathrm{mg}$ of $\mathrm{KOH}$ in $65 \mathrm{~mL}$ of methanol in a separate beaker. To a $25 \mathrm{~mL}$ portion of $0.01 \mathrm{M}$ zinc acetate dihydrate solution heated at $60^{\circ} \mathrm{C}, 13 \mathrm{~mL}$ of $0.03 \mathrm{M} \mathrm{KOH}$ was added dropwise under vigorous stirring. The solution was incubated at $60^{\circ} \mathrm{C}$ for $2 \mathrm{~h}$ with continual stirring. In the second solution, the concentration of zinc acetate dihydrate was $0.35 \mathrm{M}$ in 2-methoxyetanol. To the second seed solution which was heated to $60^{\circ} \mathrm{C}$, monoethanolamine (MEA) was added dropwise under vigorous stirring until the molar ratio of MEA to zinc acetate dihydrate was reached to $1: 1$. The second seed solution was also incubated at $60^{\circ} \mathrm{C}$ for $2 \mathrm{~h}$ with continual stirring. The measured $\mathrm{pH}$ values for monoethanolaminebased seed solution and $\mathrm{KOH}$-based seed solution were 7.69 and 8.90 , respectively.

2.2. Synthesis of $\mathrm{ZnO}$ Nanorods. The $\mathrm{ZnO}$-nanorods were synthesized on silicon substrates through a spin-coating method. Prior to coating, the silicon substrates were nicely cleaned with RCA1 and RCA2 [17] followed by buffered oxide etching (BOE) to remove the native oxide layer. The seed solutions were then spin coated on the cleaned silicon substrates at a spin speed of $3000 \mathrm{rpm}$ for $30 \mathrm{~s}$. After successive coating of each layer, the substrates were dried at $60^{\circ} \mathrm{C}$ for $10 \mathrm{~min}$ and $250^{\circ} \mathrm{C}$ for $20 \mathrm{~min}$ to remove the organic residuals. Finally, the thin films were annealed at $550^{\circ} \mathrm{C}$ for $2 \mathrm{~h}$. The growth solution was prepared by mixing zinc nitrate hexahydrate $(0.025 \mathrm{M})$ and hexamethyltetramine $(0.025 \mathrm{M})$ in $150 \mathrm{~mL}$ DI water. The growth solution was transferred to a $250 \mathrm{~mL}$ beaker under vigorous stirring for $20 \mathrm{~min}$ and then the precoated substrates were immerged horizontally inside the beaker containing the growth precursors. After that, the beaker was directly inserted in a preheated oven at $93^{\circ} \mathrm{C}$ for 6 hours to induce the growth of nanorods. After the growth induction time, the oven was ramped down to room temperature, and the substrates were washed with deionized water to remove any residual salts and were dried under nitrogen flow. The $\mathrm{ZnO}$ nanorods obtained from $\mathrm{KOH}$-based seed layer and monoethanolamine-based seed layer were categorized as sample 1 and sample 2 .

2.3. Characterization of Nanostructured $\mathrm{ZnO}$. The morphological characterization of nanostructured $\mathrm{ZnO}$ was performed using a scanning electron microscope (SEM, JSM JEOL 6460 LA) whereas the cross-sectional images were collected from Hitachi S3400n SEM instrument. The crystallinity of the $\mathrm{ZnO}$-nanorods was studied using an X-ray diffraction (XRD) with a $\mathrm{CuK} \alpha(\lambda=1.5406 \AA)$ window. The optical properties were analyzed with a photoluminescence spectroscopy (HR800, Horiba Jyobin) excited by He-Cd laser at a wavelength of $325 \mathrm{~nm}$ with a power of $20 \mathrm{~mW}$. Raman spectra of $\mathrm{ZnO}$ nanorods were collected with an argon $\left(\mathrm{Ar}^{+}\right)$laser excited at $514 \mathrm{~nm}$ with an incident power of $20 \mathrm{~mW}$ (Horiba Jyobin). For electrical characterization, circular silver electrodes were deposited on the top of $\mathrm{ZnO}$ nanorods using Auto306 vacuum thermal evaporator. Current to voltage (I-V) characterization was carried out using Keithley 2400 source meter interfaced with Lab tracer 2.0 software.

\section{Results and Discussion}

The SEM images of $\mathrm{ZnO}$ nanorods obtained on sample 1 and sample 2 are shown in Figures 1(a) and 1(b). The morphology of $\mathrm{ZnO}$ nanorods grown on sample 1 is demonstrated in Figure 1(a). The silicon substrate was densely covered with the $\mathrm{ZnO}$ nanorods. However, the synthesized nanorods were not orderly aligned to the substrate. This was reflected in the cross-sectional SEM image as shown in Figure 1(c) and its magnified view (inset of Figure 1(c)). The morphology of $\mathrm{ZnO}$ nanorods grown on sample 2 is shown in Figure 1(b). Here the silicon substrate was found to be densely covered with the perpendicularly grown well-aligned $\mathrm{ZnO}$ nanorods. This was confirmed from the cross-sectional SEM image (Figure $1(\mathrm{~d})$ ) and its magnified view (inset).

The various morphologies for the sol-gel using $\mathrm{KOH}-$ based seed layer and monoethanolamine-based seed layerderived $\mathrm{ZnO}$ nanorods can be attributed (i) to the different physiochemical properties of the monoethanolaminebased and $\mathrm{KOH}$-based seed solutions of zinc acetate dihydrate in 2-methoxyethanol and methanol, respectively. The monoethanolamine-based seed solution was thicker than the $\mathrm{KOH}$-based seed solution. MEA and $\mathrm{KOH}$ components probably provided the required basicity to the seed solutions. The monoethanolamine-based seed solution was more homogeneous and stable than that of $\mathrm{KOH}$-based seed solutions when left for long time. This might be due to the limited solubility of both zinc acetate dihydrate and $\mathrm{KOH}$ in methanol. The longer stability and homogeneity of the 2methoxyethanol solution was probably due to the stabilizing property of monoethanolamine. The different thickness of the two seed solutions produced different type of crystal and thus different $\mathrm{ZnO}$ nanorods on silicon substrates. (ii) When the quantity of alkali was small, fewer particles were appeared as reported in the literature [18]. Due to the coordination effect of $\mathrm{OH}^{-}$ions to $\mathrm{Zn}^{2+}$ ions, it is possible that $\mathrm{OH}^{-}$ions are adsorbed at the circumference of $\mathrm{Zn}$ ions of the $\mathrm{ZnO}$ nuclei. Due to the spatial hindrance, $\mathrm{ZnO}$ grew only along certain directions [19]. The $\mathrm{ZnO}$ seed crystals in monoethanolamine-based solution were bigger and more oriented than those in $\mathrm{KOH}$-based seed solutions. Moreover, the diameter of grown $\mathrm{ZnO}$ nanorods can be determined from the size of the crystal grains of seeded $\mathrm{ZnO}$ [20]. 


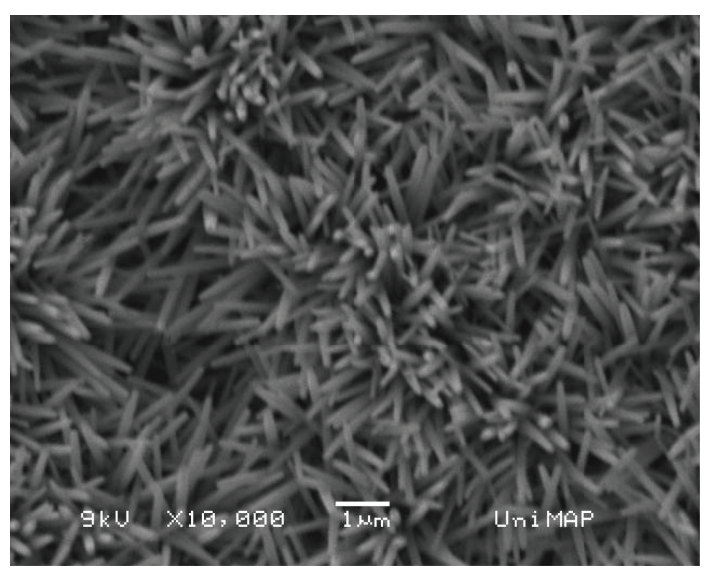

(a)

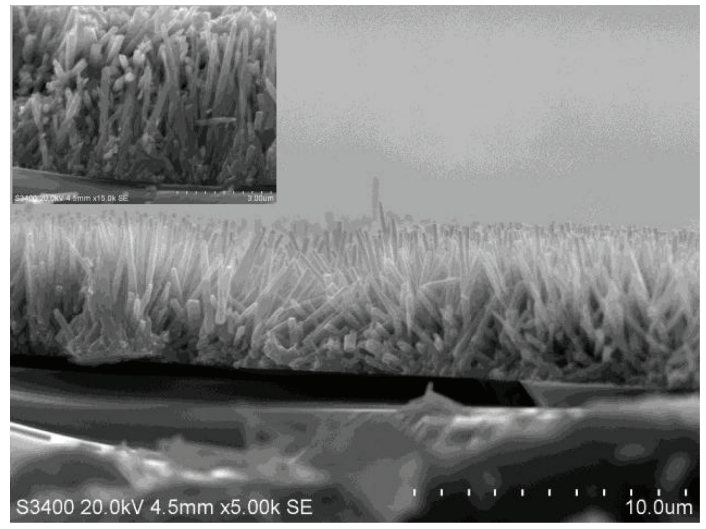

(c)

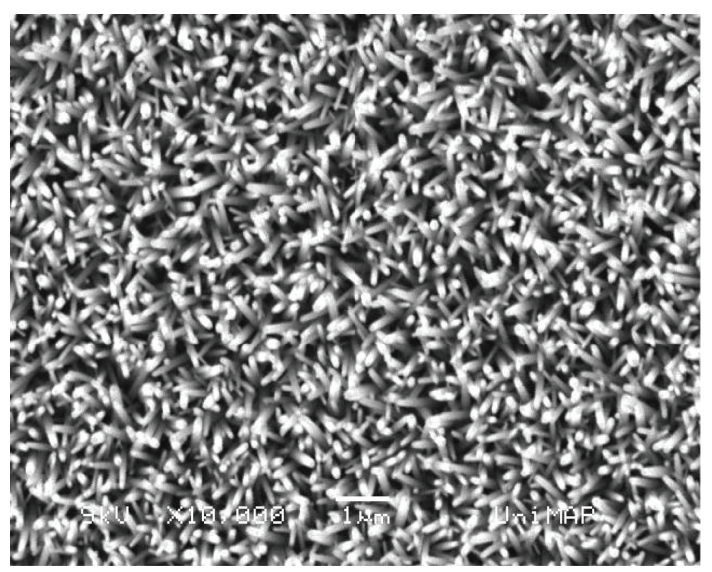

(b)

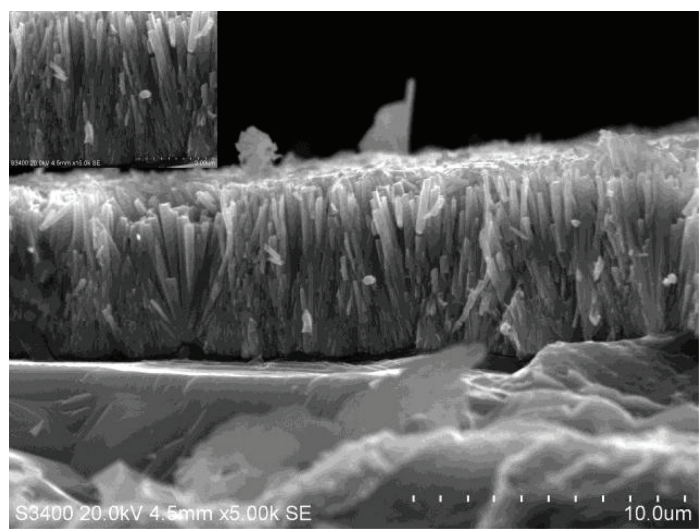

(d)

FIGURE 1: SEM images showing the surface morphologies of $\mathrm{ZnO}$ nanorods synthesized on KOH-based seed layer (a) and monoethanolamine-based seed layer (b). The cross-sectional view of the above nanostructured $\mathrm{ZnO}$ grown on $\mathrm{KOH}$ - and monoethanolamine-based seed layers is demonstrated in (c) and (d), respectively.

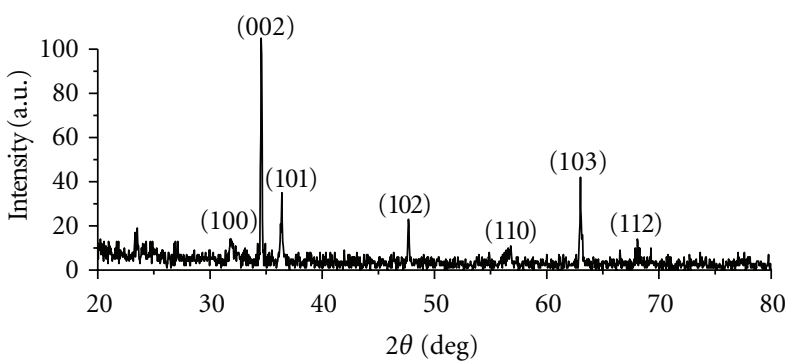

(a)

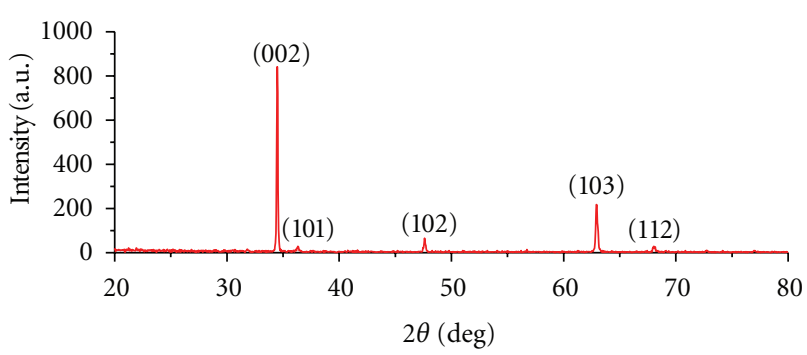

(b)

Figure 2: XRD spectra demonstrating crystal qualities of $\mathrm{ZnO}$ nanorods synthesized on $\mathrm{KOH}$-based seed layer (a) and monoethanolaminebased seed layer (b).

It was also reported earlier that growth of $\mathrm{ZnO}$ nanorods was dependent on the roughness and thickness of the seed layers. The seed layer with more rough surface and higher length can provide conditions to form the nuclei easily [21].

Figures 2(a) and 2(b) show the XRD patterns of the $\mathrm{ZnO}$ nanorods obtained from sample 1 and sample 2 . It consisted of several peaks at $\left(\begin{array}{lll}0 & 0 & 2\end{array}\right),\left(\begin{array}{lll}1 & 0 & 1\end{array}\right),\left(\begin{array}{lll}1 & 0 & 2\end{array}\right),\left(\begin{array}{lll}1 & 0 & 3\end{array}\right)$ and (lll 112 ) planes. All the diffraction peaks were indexed to the hexagonal structure of the $\mathrm{ZnO}$ according to JCPDS card
No. 036-1451. The lattice constants were calculated using the following relations:

$$
\begin{gathered}
a=\sqrt{\frac{1}{3}} \frac{\lambda}{\operatorname{Sin} \theta}, \\
c=\frac{\lambda}{\operatorname{Sin} \theta} .
\end{gathered}
$$


TABLE 1: The values of interplane distance $d(\AA)$, lattice parameters, and grain size.

\begin{tabular}{lcccc}
\hline & $a(\AA)$ & $c(\AA)$ & $d(\AA)$ & $D(\AA)$ \\
\hline Sample 1 & 2.99 & 5.185 & 2.593 & 483 \\
Sample 2 & 3.001 & 5.198 & 2.599 & 667 \\
\hline
\end{tabular}

The values for " $d$ " were calculated using the following relation:

$$
d=\frac{\lambda}{(2 \operatorname{Sin} \theta)}
$$

whereas the particle size was calculated by using the Scherer's equation as follows:

$$
D=\frac{0.9 \lambda}{B \operatorname{Cos} \theta}
$$

The calculated values for lattice constant, planner distance and crystallite size at " 002 " peaks are tabulated in Table 1.

The strongest peak $\left(\begin{array}{ll}0 & 0\end{array}\right)$ at $2 \theta=34.48^{\circ}$ and $34.57^{\circ}$ with full-width half-maximum (FWHM) of $0.1246^{\circ}$ and $0.172^{\circ}$ for sample 1 and sample 2, respectively, showed good quality crystals oriented at $c$-axis. The approximately 10 times lower intensity magnitude of nanorod $\mathrm{ZnOs}$ for sample 1 over that of sample 2 suggested that the sample 2 produced better quality crystal structures.

No other peaks of impurities such as zinc nitrate hexahydrate and hexamethyltetramine were observed in the spectra. The possible enhancement in the crystal quality of nanorod $\mathrm{ZnOs}$ using monoethanolamine-based seeded layers might be due to strain relaxation. It was found that first 10 to $40 \mathrm{~min}$ was the deciding factor for the ultimate diameter of nanorod ZnOs. The interface free energy of the seed grains and growth solution was less than the crystalvapour interface which might occur during the growth of rods. The high-interface free energy of the crystal-vapour interface could be due to the residual strains which are correlated to the heating history of growth process [22]. It is the strain relaxation which was responsible for the increased diameter of the nanorods.

Figure 3 shows the Raman scattering spectra of the nanorod $\mathrm{ZnOs}$ produced on sample 1 and sample 2. The spectra were collected by exciting laser line at $488 \mathrm{~nm}$ with excitation power of $20 \mathrm{~mW}$.

One sharp peak at $520 \mathrm{~cm}^{-1}$ and two weak peaks at $302 \mathrm{~cm}^{-1}$ and $620 \mathrm{~cm}^{-1}$ can be conferred to the TO phonon mode originating from silicon substrate [23]. The peak which appeared at $438 \mathrm{~cm}^{-1}$ with significantly high intensity is a typical characteristic of hexagonal wurtzite $\mathrm{ZnO}$. The intensity of this peak was increased in both the cases but the intensity is higher in comparison to the sample 1. This peak was assigned to the Raman active optical phonon of $\mathrm{E}_{2 \mathrm{H}}$ mode [24]. A weak peak that appeared at $327 \mathrm{~cm}^{-1}$ was assigned to multiphonon scattering process $\left(\mathrm{E}_{2 \mathrm{H}}-\mathrm{E}_{2 \mathrm{~L}}\right)$ [25]. Raman analysis also satisfied the XRD results, confirming the better quality of $\mathrm{ZnO}$ crystals in sample 2 .

To study the optical characteristics of nanorod $\mathrm{ZnOs,}$ photoluminescence spectroscopy was carried out on both

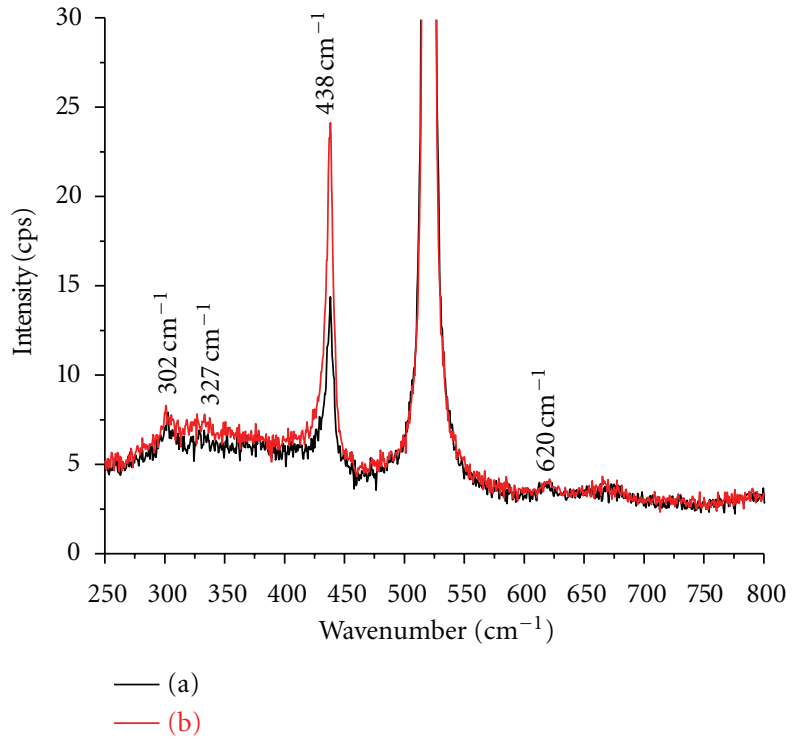

FIGURE 3: Raman spectra reflecting crystalline, structural, and orientation profiles of $\mathrm{ZnO}$ nanorods synthesized on $\mathrm{KOH}$-based seed layer (a) and monoethanolamine-based seed layer (b).

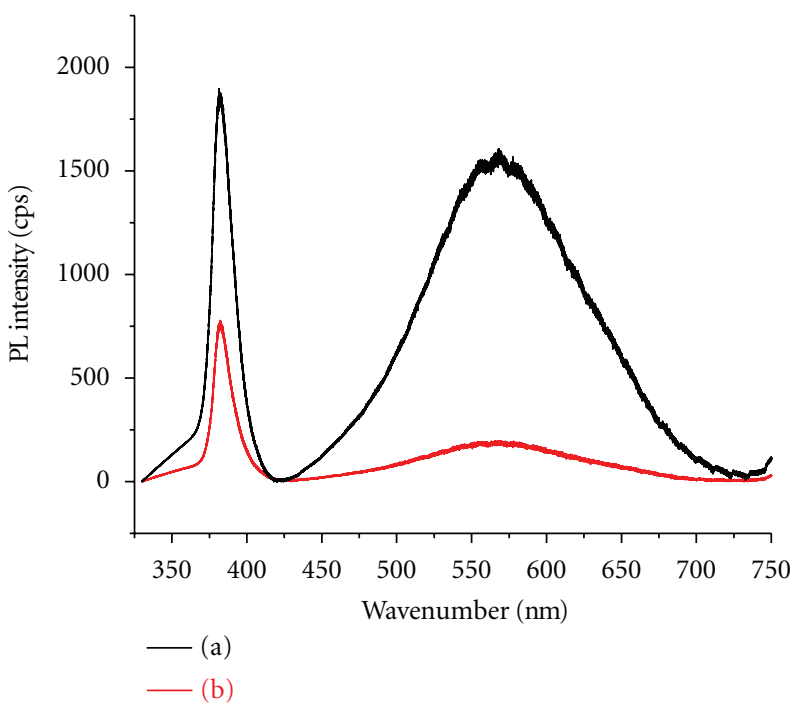

FIgURE 4: Photoluminescence spectra demonstrating optical properties of $\mathrm{ZnO}$ nanorods synthesized on $\mathrm{KOH}$-based seed layer (a) and monoethanolamine-based seed layer (b).

the samples at room temperature. The typical spectra for the photoluminescence for both the samples are shown in Figure 4. The photoluminescence spectra demonstrated a strong UV emission at $382 \mathrm{~nm}$ and a visible emission at $567 \mathrm{~nm}$. This UV band was due to the recombination of free excitons through an exciton-exciton collision process. It was documented that deep-level emissions are associated with the singly ionized oxygen vacancy in $\mathrm{ZnO}$ and results from the recombination of a photogenerated hole with the singly ionized charge state of this defect [26]. 


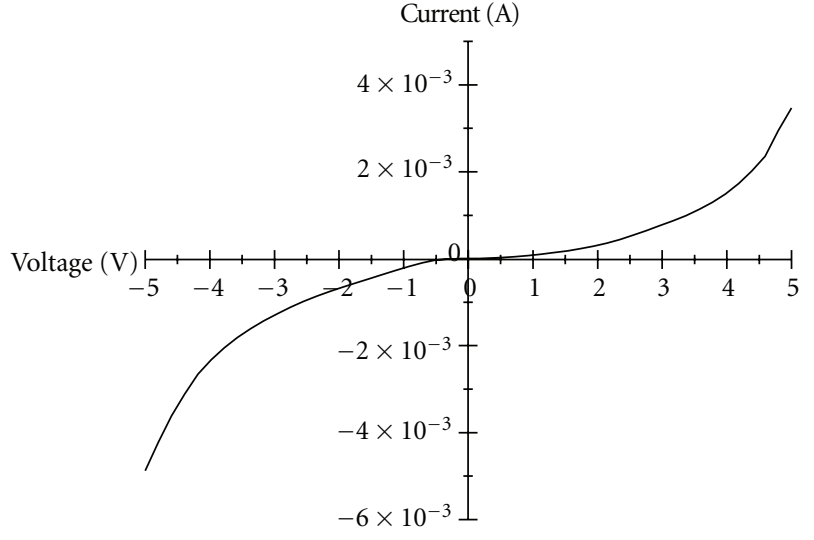

(a)

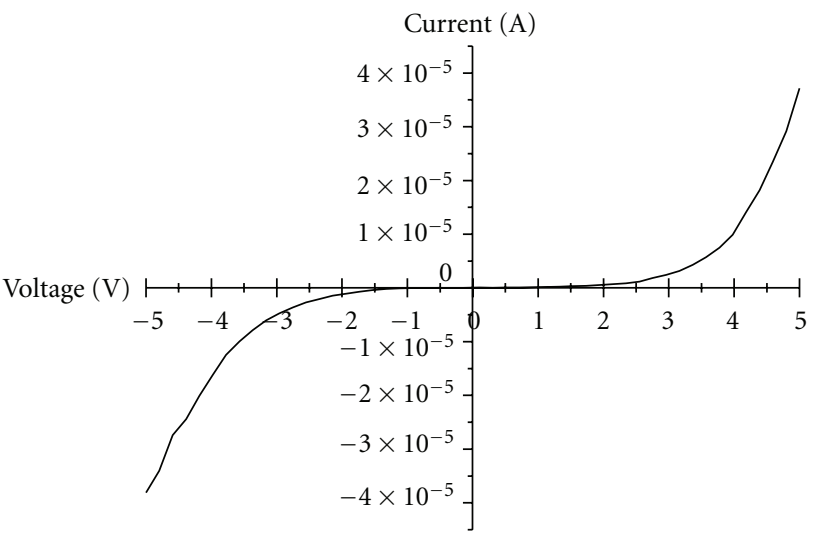

(b)

Figure 5: I-V curves showing the electrical properties of $\mathrm{ZnO}$ nanorods synthesized on $\mathrm{KOH}$-based seed layer (a) and monoethanolaminebased seed layer (b).

Usually, the visible emission from $\mathrm{ZnO}$ is attributed to different defects such as oxygen vacancies $\left(V_{O}\right)$, zinc vacancies $\left(\mathrm{V}_{\mathrm{Zn}}\right)$ or a complex defect involving interstitial zinc $\left(\mathrm{Z}_{\mathrm{ni}}\right)$, and interstitial oxygen $\left(\mathrm{O}_{\mathrm{i}}\right)$ [7]. The intensity of visible peak of sample 2 is lower as compared to the intensity of sample 1 . The decrement in the intensity of visible region as well as higher UV/Vis ratio for sample 2 suggests that sample 2 has good crystallinity. The photoluminescence results satisfied the above results of XRD and PL that sample 2 has better crystallinity than that of sample 1 .

Figure 5 shows the current to voltage (I-V) characteristic curves of nanorod $\mathrm{ZnOs}$ for sample 1 and sample 2. It was observed that sample 1 has higher conduction as compare to sample 2. This was conferred to the higher polarity of potassium hydroxide over monoethanolamine. The turn on voltage for sample 1 was approximately 1.5 volts whereas that for sample 2 was around 2.5 volts, suggesting that both the structures can be used for the optoelectronic devices with some differences in power ratings. For faster switching and less operating voltages, sample 1 was better performing, suggesting its applications in low power-consuming devices.

\section{Conclusion}

Nanorod ZnOs of two different morphologies and optoelectric properties were successfully synthesized on two different seeded layered silicon substrates. While the better crystal quality, fewer structural defect and better aligned $\mathrm{ZnO}$ nanorods were obtained through monoethanolaminebased sol-gel method, better electrical conductivity was found in nanorod $\mathrm{ZnOs}$ derived through $\mathrm{KOH}$-based solgel methods. Thus $\mathrm{KOH}$-based sol-gel method should be selected for synthesizing nanorod-ZnOs for power-saving optoelectrical devices. On the other hand, better aligned, better crystalline, and fewer defects in monoethanolaminebased sol-gel derived nanorod-ZnOs suggest their potential applications in optoelectronic devices of higher longitivity and stability.

\section{Acknowledgments}

The author would like to acknowledge the financial support for the FRGS Grant number (9003-00276) from Ministry of higher education (MOHE). The author would also like to thank the technical staff of Institute of Nano Electronic Engineering and School of Microelectronic Engineering, Universiti Malaysia Perlis for their kind support to smoothly perform the research.

\section{References}

[1] G. Chai, O. Lupan, L. Chow, and H. Heinrich, "Crossed zinc oxide nanorods for ultraviolet radiation detection," Sensors and Actuators A, vol. 150, no. 2, pp. 184-187, 2009.

[2] M. H. Asif, O. Nur, M. Willander, and B. Danielsson, "Selective calcium ion detection with functionalized $\mathrm{ZnO}$ nanorodsextended gate MOSFET," Biosensors and Bioelectronics, vol. 24, no. 11, pp. 3379-3382, 2009.

[3] R. Niepel, U. C. Schröder, J. Sommerfeld et al., "Biofunctionalization of zinc oxide nanowires for DNA sensory applications," Nanoscale Research Letters, vol. 6, article 511, 2011.

[4] M. Fakhar-e-Alam, M. U. Syed Ali, Z. Ibupoto et al., "Sensitivity of A-549 human lung cancer cells to nanoporous zinc oxide conjugated with Photofrin," Lasers in Medical Science, vol. 27, no. 3, pp. 607-614, 2012.

[5] T. Krishnakumar, R. Jayaprakash, N. Pinna et al., "CO gas sensing of $\mathrm{ZnO}$ nanostructures synthesized by an assisted microwave wet chemical route," Sensors and Actuators B, vol. 143, no. 1, pp. 198-204, 2009.

[6] B. Liu and H. C. Zeng, "Hydrothermal synthesis of $\mathrm{ZnO}$ nanorods in the diameter regime of $50 \mathrm{~nm}$," Journal of the American Chemical Society, vol. 125, no. 15, pp. 4430-4431, 2003.

[7] M. Kashif, M. Syed Usman Ali, M. E. Ali et al., "Morphological, optical, and Raman characteristics of $\mathrm{ZnO}$ nanoflakes prepared via a sol-gel method," Physica Status Solidi (A), vol. 209, no. 1, pp. 143-147, 2012.

[8] X. Wu, F. Qu, X. Zhang, W. Cai, and G. Shen, "Fabrication of $\mathrm{ZnO}$ ring-like nanostructures at a moderate temperature via a thermal evaporation process," Journal of Alloys and Compounds, vol. 486, no. 1-2, pp. L13-L16, 2009. 
[9] L. Wang, K. Chen, and L. Dong, "Synthesis of exotic zigzag $\mathrm{ZnO}$ nanoribbons and their optical, electrical properties," Journal of Physical Chemistry C, vol. 114, no. 41, pp. 1735817361, 2010.

[10] A. A. Scalisi, R. G. Toro, G. Malandrino, M. E. Fragalà, and G. Pezzotti, "Growth of $\mathrm{ZnO}$ nanostructures produced by MOCVD: a study of the effect of the substrate," Chemical Vapor Deposition, vol. 14, no. 5-6, pp. 115-122, 2008.

[11] L. Vayssieres, "Growth of arrayed nanorods and nanowires of ZnO from aqueous solutions," Advanced Materials, vol. 15, no. 5, pp. 464-466, 2003.

[12] M. Kashif, Y. Al-Douri, U. Hashim, M. E. Ali, S. M. U. Ali, and M. Willander, "Characterisation, analysis and optical properties of nanostructure $\mathrm{ZnO}$ using the sol-gel method," Micro \& Nano Letters, vol. 7, no. 2, pp. 163-167, 2012.

[13] N. Izyumskaya, V. Avrutin, W. Schoch et al., "Molecular beam epitaxy of high-quality $\mathrm{ZnO}$ using hydrogen peroxide as an oxidant," Journal of Crystal Growth, vol. 269, no. 2-4, pp. 356361, 2004.

[14] M. Senthil Kumar, D. Chhikara, and K. M. K. Srivatsa, "Structure-controlled growth of $\mathrm{ZnO}$ nanonails by thermal evaporation technique," Crystal Research and Technology, vol. 46, no. 9, pp. 991-996, 2011.

[15] X. Hu, Y. Masuda, T. Ohji, and K. Kato, "Micropatterning of $\mathrm{ZnO}$ nanoarrays by forced hydrolysis of anhydrous zinc acetate," Langmuir, vol. 24, no. 14, pp. 7614-7617, 2008.

[16] Y. Masuda, N. Kinoshita, F. Sato, and K. Koumoto, "Siteselective deposition and morphology control of UV- and visible-light-emitting ZnO crystals," Crystal Growth and Design, vol. 6, no. 1, pp. 75-78, 2006.

[17] G. M. Ali and P. Chakrabarti, "ZnO-based interdigitated MSM and MISIM ultraviolet photodetectors," Journal of Physics D, vol. 43, no. 41, Article ID 415103, 2010.

[18] Y. Lei, F. Qu, and X. Wu, "Assembling $\mathrm{ZnO}$ nanorods into microflowers through a facile solution strategy: morphology control and cathodoluminescence properties," Nano-Micro Letters, vol. 4, no. 1, pp. 45-51, 2012.

[19] Y. Ni, S. Yang, J. Hong, L. Zhang, W. Wu, and Z. Yang, "Fabrication, characterization and properties of flowerlike $\mathrm{ZnS}-\mathrm{ZnO}$ heterogeneous microstructures built up by $\mathrm{ZnS}$ particle-strewn ZnO microrods," Journal of Physical Chemistry C, vol. 112, no. 22, pp. 8200-8205, 2008.

[20] W. Wu, G. Hu, S. Cui, Y. Zhou, and H. Wu, "Epitaxy of vertical $\mathrm{ZnO}$ nanorod arrays on highly (001)-oriented $\mathrm{ZnO}$ seed monolayer by a hydrothermal route," Crystal Growth and Design, vol. 8, no. 11, pp. 4014-4020, 2008.

[21] M. Y. Cho, M. S. Kim, H. Y. Choi, K. G. Yim, and J. Y. Leem, "Post-annealing effects on properties of $\mathrm{ZnO}$ nanorods grown on Au seed layers," Bulletin of the Korean Chemical Society, vol. 32, no. 3, pp. 880-884, 2011.

[22] Y. T. Yin, W. X. Que, and C. H. Kam, "ZnO nanorods on $\mathrm{ZnO}$ seed layer derived by sol-gel process," Journal of Sol-Gel Science and Technology, vol. 53, no. 3, pp. 605-612, 2010.

[23] M. Willander, L. L. Yang, A. Wadeasa et al., "Zinc oxide nanowires: controlled low temperature growth and some electrochemical and optical nano-devices," Journal of Materials Chemistry, vol. 19, no. 7, pp. 1006-1018, 2009.

[24] Y. J. Xing, Z. H. Xi, Z. Q. Xue et al., "Optical properties of the $\mathrm{ZnO}$ nanotubes synthesized via vapor phase growth," Applied Physics Letters, vol. 83, no. 9, pp. 1689-1691, 2003.

[25] H. J. Fan, R. Scholz, F. M. Kolb et al., "On the growth mechanism and optical properties of $\mathrm{ZnO}$ multi-layer nanosheets," Applied Physics A, vol. 79, no. 8, pp. 1895-1900, 2004.
[26] S. Mridha and D. Basak, "Effect of concentration of hexamethylene tetramine on the structural morphology and optical properties of $\mathrm{ZnO}$ microrods grown by low-temperature solution approach," Physica Status Solidi (A), vol. 206, no. 7, pp. 1515-1519, 2009. 

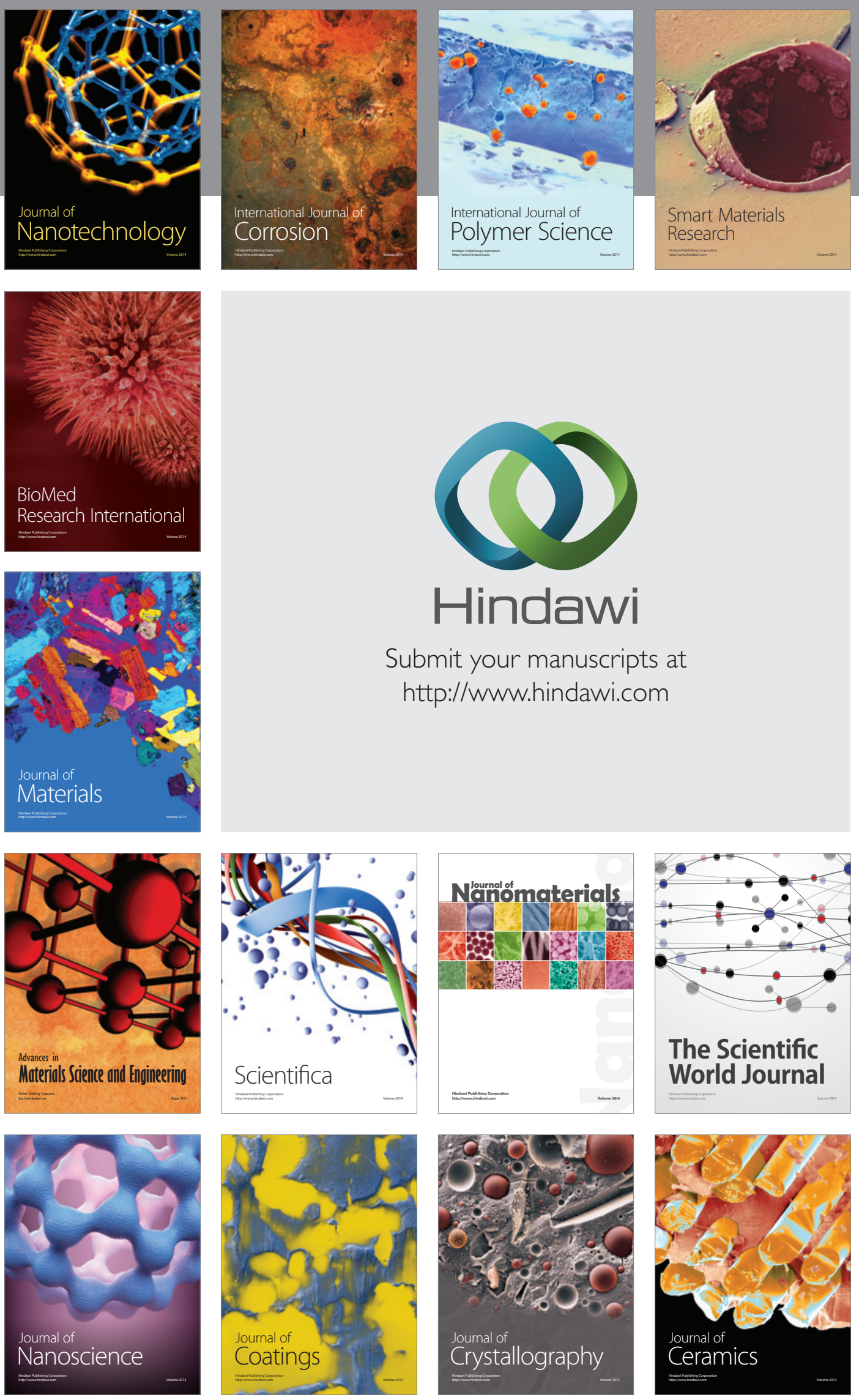

The Scientific World Journal

Submit your manuscripts at

http://www.hindawi.com

\section{World Journal}

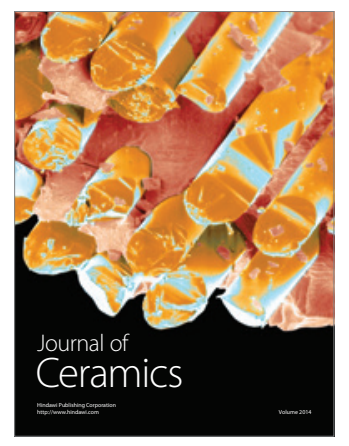

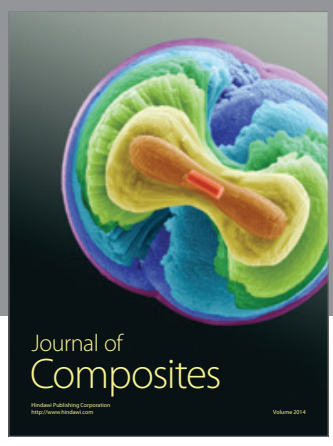
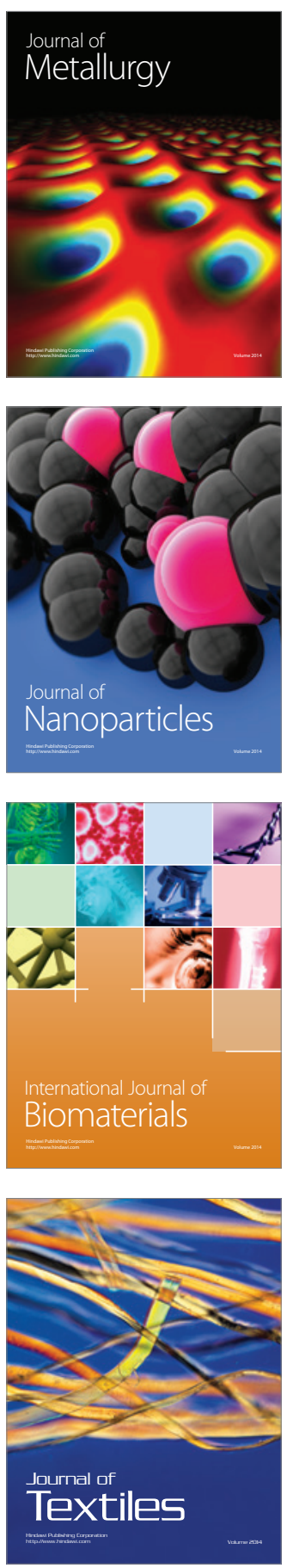